\title{
ASPECTS REGARDING GRINDED SALIX VIMINALIS DISTRIBUTION AND ENERGY CONSUMPTION USING HAMMER MILL
}

\author{
Georgiana Moiceanu, Mirela-Nicoleta Dinca, Gigel Paraschiv, Gheorghe Voicu \\ University Politehnica of Bucharest, Romania \\ moiceanugeorgiana@gmail.com, mirela_dilea@yahoo.com, paraschiv2005@yahoo.com, \\ ghvoicu_2005@yahoo.com
}

\begin{abstract}
In the recent years, the interest in renewable energy resources has increased because of the rising energy demand and fuel costs, environmental concerns and limited sources of fossil fuels. Energy crops are frequently used in the production of environmentally friendly fuels such as: pellets and briquettes, biogas, biodiesel and bioethanol. Pelleting and briquetting processes have been used for many years to produce densified biomass for fuel applications. Pelletizing of biomass involves grinding, conditioning by applying heat and/or moisture, and forcing the sample through die. The main parameters that influence the pelleting process are the particle size, preheating temperature and die rotational speed. Particle size of the feedstock influences the binding phenomena as smaller size particles have more surface area or contact area and facilitate better binding. In the present paper, using Salix Viminalis as biomass, the grinding process was analyzed using a hammer mill MC 22 equipped with different sieve orifice diameter $(\varnothing 7 \mathrm{~mm}$ and $\varnothing 10 \mathrm{~mm})$, four types of hammers and the rotor speed ranged from $2400 \mathrm{rpm}$ to $3000 \mathrm{rpm}$. The energy consumption necessary for the grinding process was researched and compared between the two types of sieves in order to obtain lower energy consumption for milling. The distribution of grinded Salix Viminalis for each type of hammer taking into consideration the rotor frequency is also presented. In the paper, the results obtained present, which hammer can be regarded as an optimum for a certain value of rotor frequency.
\end{abstract}

Keywords: biomass grinding, hammer mill, energy consumption, rotor frequency.

\section{Introduction}

Lately, decreasing greenhouse gas emissions to the atmosphere and the independence of global economy from fossil fuels are the main arguments to use renewable resources for energy production [1]. Lignocellulosic crops like Miscanthus (Miscanthus x giganteus) and willow (Salix viminalis) can have an interesting future as energy crops in European countries [2]. One of the major limitations of using biomass as a feedstock for bioenergy products is its low bulk density, which typically ranges from $80-100 \mathrm{~kg} \cdot \mathrm{m}^{-3}$ for agricultural straws and grasses and $150-200 \mathrm{~kg} \cdot \mathrm{m}^{-3}$ for woody resources like wood chips and sawdust. In order to overcome this limitation, the biomass density must be increased [3]. Pelleting and briquetting processes have been used for many years to produce densified biomass for fuel applications. Pellets are made from biomass that is hammer milled into fine pieces and then processed into cylindrical pellets under high pressure and temperature [4]. Size reduction is an important stage in the pelleting process. It influences a range of parameters, such as compaction, contact between particles and friction in the die [5]. In literature, the majority of researches in pelleting process use a hammer mill screen size between 0.5 and $8 \mathrm{~mm}$ and a size limit of $5 \mathrm{~mm}$ is suggested $[6 ; 7]$.

Găgeanu et al. investigated the process of pelleting Salix Viminalis depending on the humidity and granulation. They concluded that the best pellets in terms of humidity, length, surface characteristics, calorific power and ash content were obtained for the particle size of about $3 \mathrm{~mm}$ and humidity of $9 \%[8]$.

Noorfidza and Muhammad [9] also reported that the particle size contributes to the mechanical strength of biomass pellets: biomass pellets made with a smaller particle size showed high yield stress and density. They tested the particle size of biomass in range of 150-300, 300- 425 and 425-600 $\mu \mathrm{m}$.

The specific energy requirements for biomass densification depend on many variables, such as: process variables: temperature and pressure, feedstock variables: moisture content and particle size and also biochemical composition variables: presence of starch, protein and lignocellulosic biomass composition [10].

The aim of the present paper was to determine the energy consumption necessary for willow (Salix Viminalis) grinding using a hammer mill type MC-22 equipped with a sieve with different orifice sizes $(\varnothing 7 \mathrm{~mm}$ and $\varnothing 10 \mathrm{~mm}$ ), four types of hammers and the rotor speed ranged from $2400 \mathrm{rpm}$ to $3000 \mathrm{rpm}$. 


\section{Materials and methods}

Experimental research was conducted using shredded biomass of energetic willow (Salix viminalis) at harvest, which was subjected to a milling process using a hammer mill type MC-22. The grinded energetic willow had the particle size between $25-47 \mathrm{~mm}$. The biomass moisture at the time of the milling process ranged between 8.89-11.99\%. The hammer mill type MC-22 (Fig. 1) is equipped with a $22 \mathrm{~kW}$ electrical engine and has a milling capacity of $0.22-0.42 \mathrm{~kg}^{-1}$, the rotor length is $500 \mathrm{~mm}$, the diameter of the hammers disposal is $\varnothing 220 \mathrm{~mm}$ and the grinding chamber diameter is $\varnothing 500 \mathrm{~mm}$.

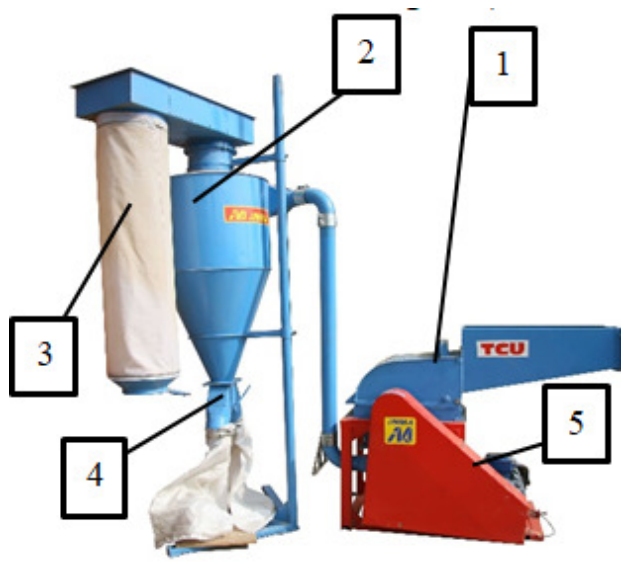

Fig. 1. Hammer mill MC 22: 1 - hammer mill; 2 - exhauster; 3 - cyclone with support and dust collector bag; 4 - grinding material evacuation vent; 5 - electric motor

During the experimental research, interchangeable sieves with orifice sizes of $\varnothing 7 \mathrm{~mm}$ and $\varnothing 10$ $\mathrm{mm}$ were used and the rotor speed ranged from $2400 \mathrm{rpm}$ to $3000 \mathrm{rpm}$ (in steps of $150 \mathrm{rpm}$ ). The material was grinded through hitting and shearing between hammers mounted on the hammer disk and counter knives. The hammers used in the experiments had several shapes, such as: A - with an edge; B - with two edges; $\mathrm{C}$ - with three edges and D - with bevelled corners. During the milling process, the required energy consumption was determined depending on the hammer type, the rotor speed and also the used sieve. The biomass quantity subjected to the milling process was $4 \mathrm{~kg}$, the grinding time being variable.

The grinded biomass was then subjected to a granulometric sorting process using the sieves of a classifier type AS 200 basic, the grinding time being about two minutes. The sieves had holes of 4 , respectively $7 \mathrm{~mm}$ in the case of a $\emptyset 7 \mathrm{~mm}$ sieve and of 4, 7, respectively $10 \mathrm{~mm}$ for a $\emptyset 10 \mathrm{~mm}$ sieve.

\section{Results and discussion}

The obtained results after the experimental research are presented in Table 1.

Variation of grinding energy depending on the hammer mill parameters

Table 1

\begin{tabular}{|c|c|c|c|c|c|}
\hline $\begin{array}{c}\text { Sieve holes } \\
\text { diameter } \\
\text { mm }\end{array}$ & $\begin{array}{c}\text { Rotor } \\
\text { frequency } \\
\text { rpm }\end{array}$ & $\begin{array}{c}\text { Hammer } \\
\text { type A } \\
\mathbf{k J} \cdot \mathbf{k g}^{-1}\end{array}$ & $\begin{array}{c}\text { Hammer } \\
\text { type B } \\
\mathbf{k J} \cdot \mathbf{k g}^{-1}\end{array}$ & $\begin{array}{c}\text { Hammer } \\
\text { type C. } \\
\mathbf{k J} \cdot \mathbf{k g}^{-1}\end{array}$ & $\begin{array}{c}\text { Hammer } \\
\text { type D } \\
\mathbf{k J} \cdot \mathbf{~ k g}^{-1}\end{array}$ \\
\hline 10 & 3000 & 42.809 & 34.120 & 47.559 & 36.851 \\
\hline 10 & 2850 & 40.255 & 33.422 & 47.326 & 30.553 \\
\hline 10 & 2700 & 35.696 & 29.168 & 27.934 & 26.936 \\
\hline 10 & 2550 & 45.534 & 35.949 & 29.647 & 23.906 \\
\hline 10 & 2400 & 49.572 & 28.371 & 40.545 & 35.522 \\
\hline 7 & 3000 & 40.959 & 33.434 & 57.755 & 33.942 \\
\hline 7 & 2850 & 57.615 & 35.083 & 51.149 & 27.591 \\
\hline 7 & 2700 & 30.738 & 29.649 & 26.179 & 34.860 \\
\hline 7 & 2550 & 42.295 & 47.729 & 38.873 & 42.205 \\
\hline 7 & 2400 & 27.171 & 45.044 & 40.117 & 36.196 \\
\hline
\end{tabular}


The grist factions have been reported to the sample amount of material and the obtained percentages have been processed using MS Excel. In Table 2 and Table 3, the material percentages on each of the classifier sieves depending on the hammer type and the hammer mill speed, are presented. Based on the results from Table 2 and Table 3, the distribution curves of the grinded material were plotted depending on the rotor speed and on the used hammer type, for the two sieve types of the grinding chamber. As it can also be observed in Figure 2, the five points used in order to graphically represent the experimental data represent each speed of revolution $(2400,2550,2700,2850$ and 3000 rpm).

Table 2

\section{Experimental results regarding the grinded material size distribution for the mill sieve of $7 \mathbf{~ m m}$}

\begin{tabular}{|c|c|c|c|c|c|c|c|c|c|c|c|c|}
\hline \multirow{2}{*}{$\begin{array}{c}\text { Rotor } \\
\text { speed } \\
\text { rpm }\end{array}$} & \multicolumn{9}{|c|}{\begin{tabular}{c} 
Percentage of material on the sieve, \% \\
\cline { 2 - 15 }
\end{tabular}} & \multicolumn{4}{|c|}{$\begin{array}{c}\text { Particles size } \\
\text { A }\end{array}$} & B & C & D & A & \multicolumn{4}{c|}{$\begin{array}{c}\text { Particles size between } \\
\text { B }\end{array}$} & \multicolumn{6}{c|}{ C } & D & A & B & C & D \\
\hline 3000 & 15 & 19 & 31 & 24 & 50 & 55 & 47 & 43 & 35 & 26 & 21 & 32 \\
\hline 2850 & 24 & 29 & 24 & 18 & 51 & 50 & 43 & 42 & 24 & 21 & 33 & 39 \\
\hline 2700 & 23 & 27 & 26 & 23 & 49 & 48 & 45 & 37 & 28 & 23 & 29 & 39 \\
\hline 2550 & 20 & 20 & 24 & 21 & 53 & 56 & 44 & 41 & 26 & 24 & 32 & 37 \\
\hline 2400 & 38 & 20 & 19 & 31 & 41 & 50 & 48 & 40 & 22 & 30 & 32 & 29 \\
\hline
\end{tabular}

Experimental results regarding the grinded material size distribution for the mill sieve of $10 \mathrm{~mm}$

\begin{tabular}{|c|c|c|c|c|c|c|c|c|}
\hline \multirow{2}{*}{$\begin{array}{c}\text { Rotor } \\
\text { speed } \\
\text { rpm }\end{array}$} & \multicolumn{7}{|c|}{ Percentage of material on the sieve, \% } \\
\cline { 2 - 10 } & $\begin{array}{c}\text { Hammer } \\
\text { type A }\end{array}$ & $\begin{array}{c}\text { Hammer } \\
\text { type B }\end{array}$ & $\begin{array}{c}\text { Hammer } \\
\text { type C }\end{array}$ & $\begin{array}{c}\text { Hammer } \\
\text { type D }\end{array}$ & $\begin{array}{c}\text { Hammer } \\
\text { type A }\end{array}$ & $\begin{array}{c}\text { Hammer } \\
\text { type B }\end{array}$ & $\begin{array}{c}\text { Hammer } \\
\text { type C }\end{array}$ & $\begin{array}{c}\text { Hammer } \\
\text { type D }\end{array}$ \\
\hline 3000 & 10 & 17 & 21 & 18 & 38 & 38 & 31 & 32 \\
\hline 2850 & 22 & 13 & 12 & 15 & 31 & 37 & 34 & 23 \\
\hline 2700 & 28 & 16 & 13 & 23 & 31 & 32 & 30 & 29 \\
\hline 2550 & .22 & 16 & 20 & 10 & 27 & 32 & 27 & 30 \\
\hline 2400 & 16 & 17 & 14 & 9 & 19 & 35 & 32 & 24 \\
\hline & \multicolumn{2}{|c|}{ Particles size between 7-10 mm } & \multicolumn{5}{c|}{ Particles size > 10 mm } \\
\hline & Hammer & Hammer & Hammer & Hammer & Hammer & Hammer & Hammer & Hammer \\
type A & type B & type C & type D & type A & type B & type C & type D \\
\hline 3000 & 30 & 26 & 28 & 30 & 21 & 18 & 19 & 19 \\
\hline 2850 & 24 & 32 & 31 & 34 & 22 & 17 & 22 & 27 \\
\hline 2700 & 25 & 31 & 33 & 26 & 16 & 19 & 24 & 21 \\
\hline 2550 & 25 & 31 & 30 & 29 & 26 & 21 & 23 & 30 \\
\hline 2400 & 28 & 28 & 28 & 33 & 37 & 20 & 25 & 33 \\
\hline
\end{tabular}

As it can be seen from Table 2 and the graphs in Figure 2, the highest percentage of material particles for the mill sieve with the orifice sizes of $\emptyset 7 \mathrm{~mm}$ was recorded for 4 and $7 \mathrm{~mm}$ fractions. At the same time, if analyzing the distribution of the material on the sieves, we observe the highest percentage of grinded biomass for the A and B hammer type and particles between 4 and $7 \mathrm{~mm}$. The correlation coefficient in the variation graphs has the highest value for the hammer type $\mathrm{D}$ for material particles larger than $7 \mathrm{~mm}$.

For the mill sieve with the orifice sizes of $10 \mathrm{~mm}$, as shown in Table 3 and Figure 2, the highest percentage of material, regardless of the hammer type, was recorded for the material particles between 4 and $7 \mathrm{~mm}$, and the lowest for material particles less than $4 \mathrm{~mm}$. Also, from the variation graphs it can be seen that the highest correlation coefficient $R^{2}$ was obtained for the $A$ hammer type $\left(R^{2} \geq 0.85\right)$. 
If we analyse the distribution of the grinded material in terms of the rotor speed, it was noticed that for the speed of $3000 \mathrm{rpm}$ the highest percentage of material was recorded for the particle sizes between 4-7 mm, both for the sieve with orifice sizes of $\varnothing 7 \mathrm{~mm}$, and for the sieve with orifice sizes of $\varnothing 10 \mathrm{~mm}$. For each sieve curves obtained after the experimental research a polynomial regression analysis was done. This regression was chosen in order to best fit all curves; another type of regression analysis did not apply to every set of values and needed to be changed each time when a hammer of a sieve was chosen for analysis. The equation coefficients can be observed in Figure 2 for every parameter.
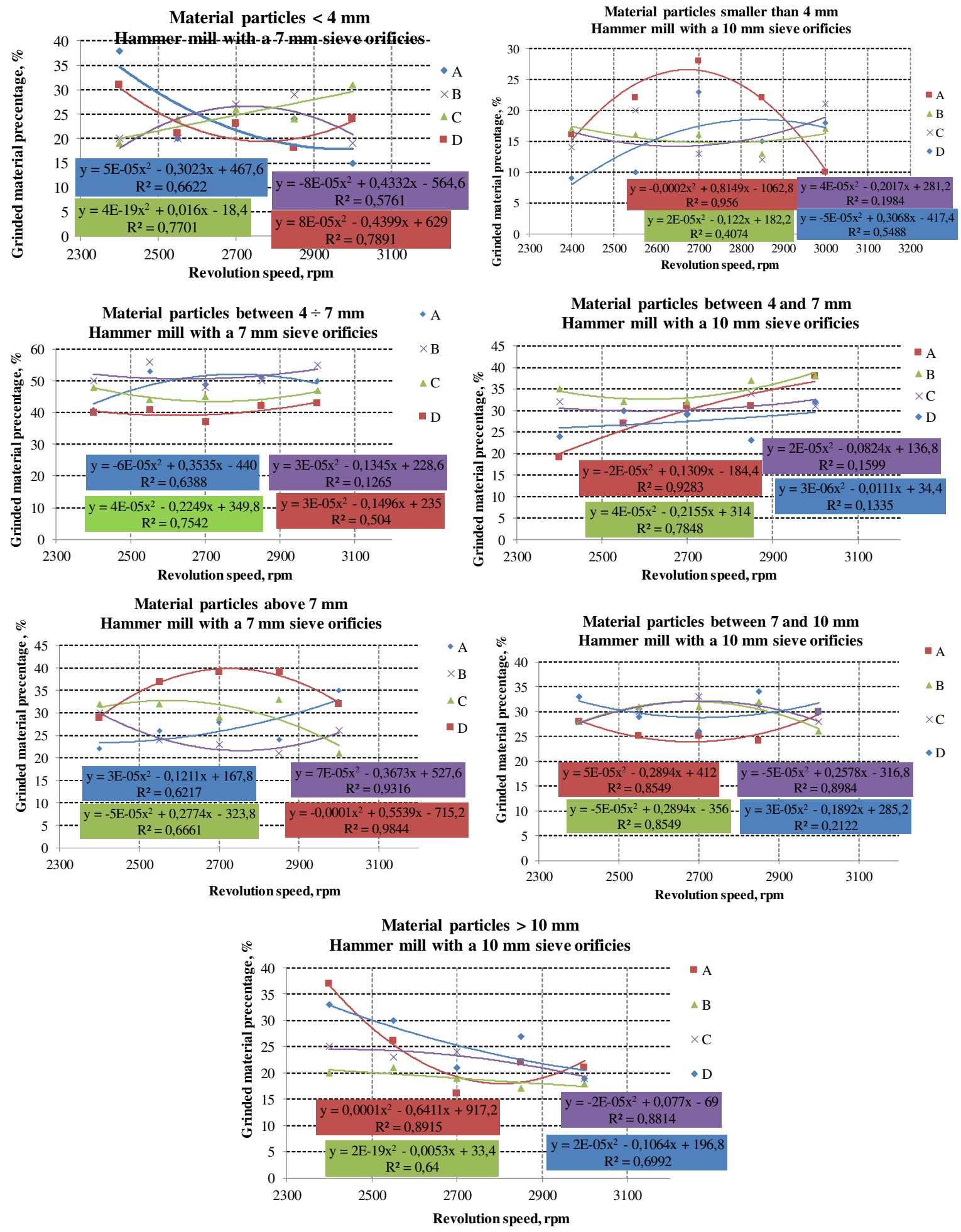

Fig. 2. Particle distribution of grinded material depending on hammer type and hammer mill speed 
For a more accurate exemplification of the energy consumption variation resulting in the milling process, the energy consumption variation for each type of sieve depending on the hammer type was plotted using the Microsoft Excel program.

If the variation of the energy consumption is analyzed, it can be seen that higher values were recorded for the sieve with orifice sizes of $7 \mathrm{~mm}$, compared to the sieve with orifice sizes of $10 \mathrm{~mm}$. The lowest energy consumption was recorded for the D hammer type at the speed of $2550 \mathrm{rpm}$ in the case of the $10 \mathrm{~mm}$ sieve, and the highest consumption was recorded for the sieve of $7 \mathrm{~mm}$, the A hammer type and the speed of $2850 \mathrm{rpm}$.

Also, from Figure 3 a variation of the specific energy consumption approximately between the same values for both sieves in the case of the D hammer type can be noticed. Similarly, if we analyze the energy variations for the $\mathrm{C}$ hammer type, higher values are observed for high speeds, average values of the energy consumption for lower speeds, and for the speed of $2700 \mathrm{rpm}$ the lowest energy value in the both cases is found. Excepting the D hammer type, average energy consumption for 2700 rpm speed for both sieves used can be noted. The highest energy consumption values, in both cases, were recorded in most cases (hammer type) for $2850 \mathrm{rpm}$.
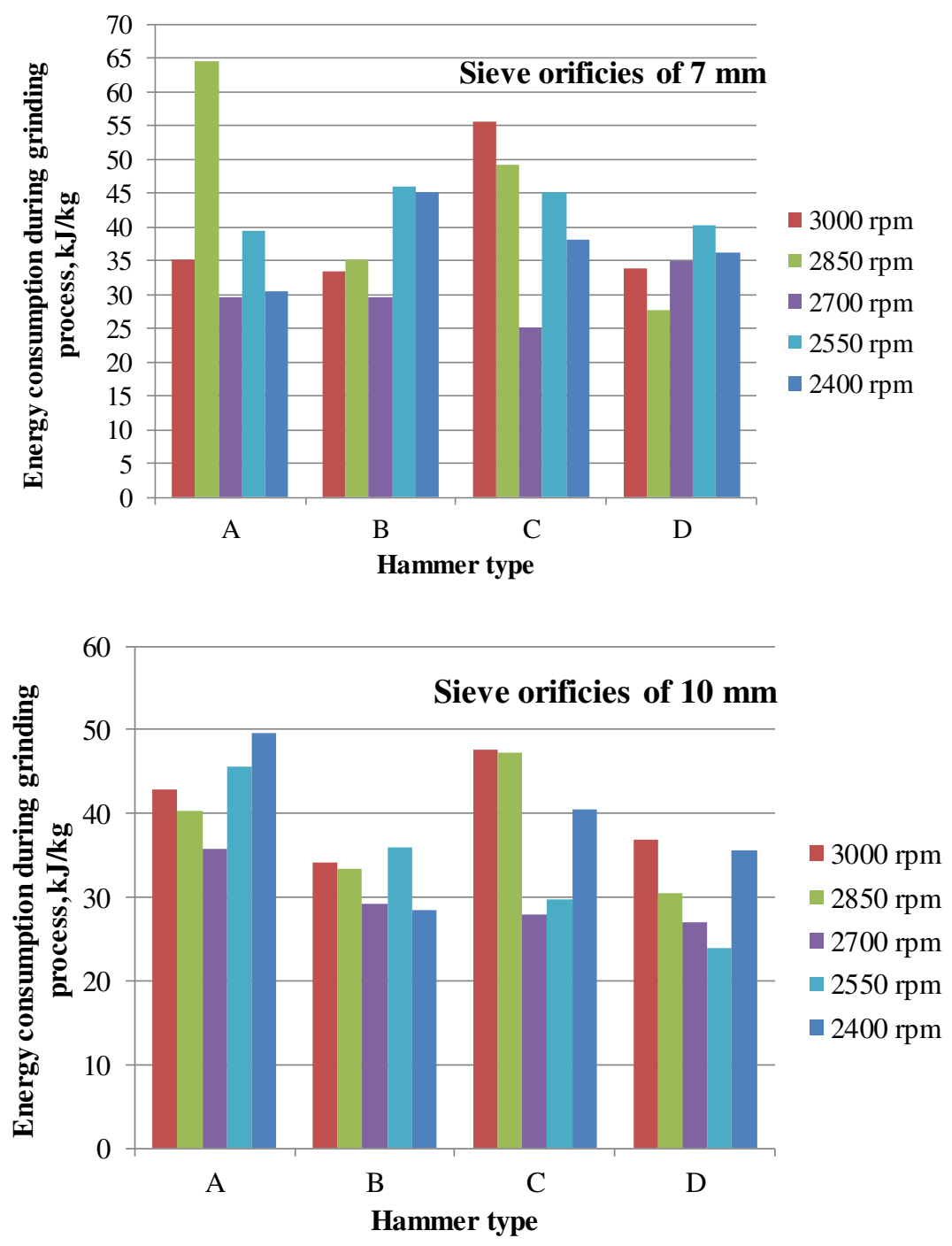

Fig. 3. Energy consumption variation depending on rotor speed

\section{Conclusions}

1. Comparing the grinded material percentage for both sieves it can be said that for the sieve with the orifice sizes of $\varnothing 7 \mathrm{~mm}$ the values are between $15-56 \%$ and for the sieve with the orifice sizes of $\emptyset 10 \mathrm{~mm}$ the values are between $9-38 \%$. 
2. A percentage of grinded material distribution was established as being lower for material sizes below $4 \mathrm{~mm}$ and over $7 \mathrm{~mm}$, with the values between $15-38 \%$ respectively $21-39 \%$ comparing to the material sizes between 4 and $7 \mathrm{~mm}$, which had a percentage of material between $37-56 \%$ for tests done with a sieve of $\varnothing 7 \mathrm{~mm}$.

3. The correlation coefficient obtained by analysing the variation of material quantity by size classes recorded higher values for the A (R2 above 0.62) and D hammer type (highest value recorded for R2 being 0,98 for particles higher than $7 \mathrm{~mm}$ ), for the sieve with the orifice sizes $\varnothing 7 \mathrm{~mm}$,

4. Considering the correlation coefficient for the sieve with the orifice sizes of $\varnothing 10 \mathrm{~mm}$ it must be said that $\mathrm{R} 2$ had for the hammer type B a value of 0.85 and for the hammer type A all correlation coefficients were above 0.85 .

5. Instead, the energy consumption recorded for Salix Viminalis biomass grinding showed a higher value for the sieve with orifice sizes of $\emptyset 7 \mathrm{~mm}$, respectively $64.52 \mathrm{~kJ} \cdot \mathrm{kg}^{-1}$.

6. Depending on the hammer type, the lowest energy consumption was recorded for the $\mathrm{C}$ with the values between $26.17-57.75 \mathrm{~kJ} \cdot \mathrm{kg}^{-1}$, respectively, the D hammer type with the values between $23.9-36.85 \mathrm{~kJ} \cdot \mathrm{kg}^{-1}$, for the sieve with orifice sizes of $\emptyset 7 \mathrm{~mm}$, respectively $10 \mathrm{~mm}$.

7. For medium speeds of $2700 \mathrm{rpm}$, medium energy consumption around $30 \mathrm{~kJ} \cdot \mathrm{kg}^{-1}$ was recorded for grinding for both types of sieves and approximately for all hammer types.

8. Following the experimental research, for each speed value, a certain type of hammer considered optimal can be indicated (for example, for speeds of $2700 \mathrm{rpm}$ and $2850 \mathrm{rpm}$, it is indicated to use a three-step hammer for minimal energy consumption).

\section{Acknowledgements}

This work was funded by the Executive Agency for Higher Education, Research, Development and Innovation Funding, within the project entitled "Optimizing the composition of biomass mixtures for obtaining high quality pellets", ctr. 24 BG / 2016 (code PN-III-P2-2.1-BG-2016-0266), Romania.

\section{References}

[1] Golinski T., Foltynowicz Z. Pellet - a key to biomass energy. International Journal of Economic Practices and Theories, vol. 2(4), 2012, pp. 197-204.

[2] Venturi P., Gigler J.K., Huisman W. Economical and technical comparison between herbaceous (Miscanthus $x$ giganteus) and woody energy crops (Salix viminalis). Renewable Energy, vol. 16 (1-4), 1999, pp. 1023-1026.

[3] Tumuluru J.S., Wright C.T., Hess J.R., Kenney K.L. A review of biomass densification systems to develop uniform feedstock commodities for bioenergy application. Biofuels, Bioproducts and Biorefining, vol. 5, 2011, pp. 683-707.

[4] Whittaker C., Shield I. Factors affecting wood, energy grass and straw pellet durability - a review. Renewable and Sustainable Energy Reviews, vol. 71, 2017, pp. 1-11.

[5] Jezerska L., Zajonc O., Vyletelek J., Zegzulka J. Mechanical material properties effect on pelletization. Wood Research, vol. 61(2), 2016, pp. 307-320.

[6] Caroll J.P., Finnan J. Physical and chemical properties of pellets from energy crops and cereal straws. Biosystems Engineering, vol. 112(2), 2012, pp. 151-159.

[7] Stelte W., Sanadi A.R., Shang L., Holm J.K., Ahrenfeldt J., Henriksen U.B. Recent developments in biomass pelletization - a review. BioResources, vol. 7(3), 2012, pp. 4451-4490.

[8] Gageanu I., Voicu Gh., Bunduchi G., Bracacescu C. Experimental research on the process of pelleting salix viminalis depending on humidity and granulation. Proceedings of 15th International Scientific Conference Engineering for rural development, May 25-27, 2016, Jelgava, Latvia, pp. 624-628.

[9] Noorfidza Y.H., Muhammad T.A. Effect of particle size on mechanical properties of pellets made from biomass blends. Procedia Engineering, vol. 148, 2016, pp. 93-99.

[10] Tumuluru J.S., Wright C.T., Kenney K.L., Hess J.R. A review on biomass densification technologies for energy application. Idaho National Laboratory, Biofuels and Renewable Energy Technologies Department, 2010. 